GRASAS Y ACEITES 68 (4)

October-December 2017, e221

ISSN-L: 0017-3495

doi: http://dx.doi.org/10.3989/gya.0553171

\title{
Calculation procedure for formulating lauric and palmitic fat blends based on the grouping of triacylglycerol melting points
}

\author{
B.P. Nusantoro ${ }^{\mathrm{a}, \mathrm{c}}$, N.A.M. Yanty ${ }^{\mathrm{d}}$, D. Van de Walle ${ }^{\mathrm{a}}$, C. Hidayat ${ }^{\mathrm{c}}$, S. Danthine $^{\mathrm{b}}$ and K. Dewettinck $^{\mathrm{a}, \bigotimes}$ \\ ${ }^{a}$ Laboratory of Food Technology and Engineering, Ghent University, Coupure links 653, B-9000 Gent, Belgium \\ ${ }^{b}$ Laboratory of Food Science and Formulation, University of Liege, Gembloux Agro-Bio Tech, Gembloux, Belgium \\ ${ }^{c}$ Department of Food and Agricultural Product Technology, Gadjah Mada University, Jl. Flora 1, Yogyakarta 55281, Indonesia \\ ${ }^{\top}$ Halal Products Research Institute, Universiti Putra Malaysia, Malaysia \\ ${ }^{\bowtie}$ Corresponding author: koen.dewettinck@ugent.be
}

Submitted: 16 May 2017; Accepted: 07 August 2017

\begin{abstract}
SUMMARY: A calculation procedure for formulating lauric and palmitic fat blends has been developed based on grouping TAG melting points. This procedure offered more flexibility in choosing the initial fats and oils and eventually gave deeper insight into the existing chemical compositions and better prediction on the physicochemical properties and microstructure of the fat blends. The amount of high, medium and low melting TAGs could be adjusted using the given calculation procedure to obtain the desired functional properties in the fat blends. Solid fat contents and melting behavior of formulated fat blends showed particular patterns with respect to ratio adjustments of the melting TAG groups. These outcomes also suggested that both TAG species and their quantity had a significant influence on the crystallization behavior of the fat blends. Palmitic fat blends, in general, were found to exhibit higher SFC values than those of Lauric fat blends. Instead of the similarity in crystal microstructure, lauric fat blends were stabilized at $\beta$ polymorph while palmitic fat blends were stabilized at $\beta$ ' polymorph.
\end{abstract}

KEYWORDS: Crystallization; Fat blend; Formulation; Lauric; Palmitic; TAG grouping

RESUMEN: Procedimiento de cálculo para la formulación de mezclas de grasas lauricas y palmíticas basadas en el agrupamiento de puntos de fusión de triacilgliceroles. Se ha desarrollado un procedimiento de cálculo para la formulación de mezclas de grasas lauricas y palmíticas basándose en la agrupación de puntos de fusión de TAG. Este procedimiento ofreció más flexibilidad en la elección de las grasas y aceites iniciales y, dio una visión más profunda de las composiciones químicas existentes y una mejor predicción sobre las propiedades físico-químicas y la microestructura de las mezclas de grasas. La cantidad de TAGs de fusión alta, media y baja se pudo ajustar usando el procedimiento de cálculo dado para obtener las propiedades funcionales deseadas en las mezclas de grasas. El contenido de grasa sólida y el comportamiento de fusión de las mezclas de grasas formuladas mostraron patrones particulares con respecto a los ajustes de relación de los grupos de fusión de TAG. Estos resultados también sugirieron que tanto las especies de TAG como su cantidad tenían una influencia significativa en el comportamiento de cristalización de las mezclas de grasas. Las mezclas de grasas palmíticas, en general, mostraron valores de SFC más altos que los de las mezclas de grasas lauricas. En lugar de la similitud en la microestructura de cristales, las mezclas de grasas lauricas se estabilizaron en el polimorfo $\beta$ mientras que las mezclas de grasas palmíticas se estabilizaron en el polimorfo $\beta$ '.

PALABRAS CLAVE: Cristalización; Formulación; Laurico; Mezcla de grasas; Palmítico; TAG agrupación

ORCID ID: Nusantoro BP http://orcid.org/0000-0003-4156-6791, Yanty NAM http://orcid.org/0000-0002-3421-5494, Van de Walle D http://orcid.org/0000-0003-1018-1696, Hidayat C http://orcid.org/0000-0001-6540-5306, Danthine S http://orcid.org/0000-0002-0008-676X, Dewettinck K http://orcid.org/0000-0001-5050-2269

Citation/Cómo citar este artículo: Nusantoro BP, Yanty NAM, Van de Walle D, Hidayat C, Danthine S, Dewettinck. 2107. Calculation procedure for formulating lauric and palmitic fat blends based on the grouping of triacylglycerol melting points. Grasas Aceites 68 (4), e221. http://dx.doi.org/10.3989/gya.0553171

Copyright: (C2017 CSIC. This is an open-access article distributed under the terms of the Creative Commons Attribution (CC-by) Spain 3.0 License. 


\section{INTRODUCTION}

Fats and oils play an important role not only by providing basic nutrients for humans but also by serving as functional ingredient in various prepared foods. They greatly affect the properties of food products and their texture and flavor. Vegetable fats and oils are mainly used in the development of both fatty foods (i.e. shortening, margarine) and liquid oil products (i.e. frying oil, salad oil). For visco-elastic products, the success of their formulation is determined by the careful choice of fats and oils from natural sources followed by appropriate manipulation or modification processes. The design of prepared fatty foods then relies greatly on the effective exploitation of different functional fats and the properties of oils (Podmore, 2008).

The properties of vegetable fats and oils are unique. Lubricity, structure, clarity, consistency, plasticity, emulsification, creaming property, spreadability, aeration, hardness, freezing stability, flavor (odor, taste and mouth feel) and flavor stability are important functional attributes that should be taken into consideration for product development. The formulation of a fat-rich product is commonly initiated with the identification of these key functional properties. Further, it has been acknowledged that some of these physical properties can be strongly correlated with their products' functionalities. For example, mouth feel and flavor release can be controlled by the oxidative stability and melting properties. The fat-rich product formulation is therefore meant to identify the physical/ structural properties that can produce the intended functionalities (O'Brien et al., 2005; Avramenko and Kraslawski, 2008).

Physicochemical properties of fats and oils are mostly determined by their individual chemical substances. Refined vegetable fats and oils are simply present as a set of triacylglycerol (TAG) compounds. When the TAG species of initial fats and oils are known, it will bring advantages for the blend formulation as the chemical composition directly correlated to their functional properties. In addition, the melting point of individual TAG will play an important role as fatty foods may be present at different temperatures during their life cycle. The general pertinent temperatures of a product can be at body temperature (when being consumed), at room temperature (when used as ingredients) or at chilled temperature (when being stored in the fridge) (Dijkstra, 2008).

To indicate those distinct physical states of fat blends at different temperatures, O'Brien (O'Brien, 2008) classified the TAG species into four groups based on their melting points. The first and second groups are TAG species found to be liquid at room temperature. They may give lubricity and clarity in the fat system. The third group consists of TAGs that have a melting point range between 25 to $45{ }^{\circ} \mathrm{C}$. They affect the structure and oral properties. The last group is those that have melting points above $45^{\circ} \mathrm{C}$ and function as stabilizer and moisture barrier. In fat blends, it is expected that the liquid oil fraction suspends the solid fat fraction in an apparently solid product with good plasticity attributes.

There are sorts of vegetable fats and oils that can be found in the market, whether modified or in their natural form. The liquid oils contain mostly low melting TAGs such as OOO (e.g. High Oleic Sunflower Oil), LnLnLn (e.g. Sunflower Oil) and LnOLn (e.g. Soybean Oil). The hard fats contain mostly high melting TAGs such as PPP (e.g. Palm Stearin) and SSS (e.g. fully hydrogenated fat). In between, there are fats and oils having middle melting TAGs as their major constituents such as LaLaLa/LaLaM (e.g. Coconut oil, Palm kernel oil) and POS or POP (e.g. Cocoa butter, Kokum butter, Illipe fat) (Ghotra et al., 2002; Manaf et al., 2014). With regard to TAG composition of the fat blends, fat-rich foods can be formulated from those fats and oils to have the desired functional properties.

The aim of this study was to develop a calculation procedure for formulating lauric and palmitic fat blends based on the grouping of TAG melting points. Ternary fat blends containing low, medium and high melting fats were used as the model system because the distribution of TAG can be easily fitted and adjusted into different melting groups. In addition to TAG distribution, DSC crystallization properties, SFC, XRD and fat microstructure probed by PLM were used as physicochemical parameters to validate the formulation of the fat blends. Eventually, a distinct correlation between the grouping of TAGs in the fat blends and their physicochemical and crystallization properties may be drawn.

\section{Nomenclature}

$C, R, B, H \quad$ Chilled, Room, Body and Heated melting TAG groups

\section{$B H \quad$ The sum of B-group and H-group}

$X, Y, Z \quad$ Raw materials: indicated as high melting fat, medium melting fat and liquid oil

$U, W \quad$ The ratio of constituted materials in the first and second blend

$R \quad$ The ratio of $\mathrm{H}$-group to $\mathrm{BH}$-groups

$M \quad$ The formulated fat blend 


\section{MATERIALS AND METHODS}

\subsection{Materials}

All vegetable oils and fats were commercial products and the chemicals for analysis were those of the high purity grade. High oleic sunflower oil/HOSO and both palm kernel oil/PKO and palm stearin IV-12/POS ${ }^{2}$ were gifts from Oleon (Belgium) and Loders Crocklaan (the Netherlands), respectively. Palm olein/POO and palm stearin IV-27/POS ${ }^{1}$ were obtained from local Malaysian refineries and soybean oil/SBO was purchased from a local supermarket.

\subsection{Physicochemical analysis}

\subsubsection{Quality parameters of the initial fats and oils}

The AOCS recommended methods (Firestone, 1998) were used to determine iodine value/IV (method Cd 1-25), free fatty acid/FFA content (method $\mathrm{Ca} 5 \mathrm{a}-40)$, peroxide value (method $\mathrm{Cd}$ 8-53) and $p$-Anisidine value/AV (Cd 18-90). All samples were measured in triplicate.

\subsubsection{Triacylglycerol profile}

TAG Composition by NARP-HPLC. The TAG composition based on the equal carbon number was determined by non-aqueous reversed-phase high performance liquid chromatography (NARPHPLC). The chromatographic system consisted of a Thermo Fisher Scientific HPLC fitted with a C-18 column. Detection was done by an evaporative light scattering detector (ELSD). An optimized method developed by Rombaut et al. (2009) was used for the measurement. Elution was carried out using an acetonitrile/dichloromethane gradient at $0.72 \mathrm{~mL} / \mathrm{min}$. Results were processed by Chromquest 5.0 software (Thermo Fisher Scientific, Belgium).

Unsaturation degree of $T A G$ by $\mathrm{Ag}^{+}-$HPLC. The separation of TAGs in silver ion HPLC is based on the interaction between the silver ion and the double bonds of the carbon chain on the fatty acid moieties. The chromatographic system consisted of a Thermo Fisher Scientific HPLC, a ChromSpher 5 Lipids column and an ELSD detector. The elution was carried out using an aceton/hepthane gradient at $1 \mathrm{~mL} / \mathrm{min}$ (Nusantoro et al., 2016). The results were processed by Chromquest 5.0 software (Thermo Fisher Scientific, Belgium).

\subsubsection{Crystallization behavior by DSC}

Thermal analyses of the samples were performed on a TA Q1000 differential scanning calorimetry (TA Instruments, USA) for the lauric fat blends and a Mettler Toledo differential scanning calorimeter (DSC 823 Model) for the palmitic fat blends.
Both were equipped with a refrigerated cooling system. Nitrogen was used to purge the system. The samples $(5-15 \mathrm{mg})$ were hermetically sealed in aluminum pans. An empty pan was used as a reference during the measurements. The time-temperature program of the measurements was held at $90{ }^{\circ} \mathrm{C}$ for $10 \mathrm{~min}$ and then cooled at a rate of $5{ }^{\circ} \mathrm{C} / \mathrm{min}$ to a temperature $-60{ }^{\circ} \mathrm{C}$. The obtained data were processed by the bundled software.

\subsubsection{Solid fat content/SFC by $p N M R$}

Solid fat content was measured according to the official IUPAC method by a Maran Ultra NMR (Oxford instruments, UK) equipped with R4 cryostat cooler (Grant Instruments, UK). NMR tubes (Bruker, Germany) were used for the direct SFC measurement. The sample in the NMR tube was melted at $70{ }^{\circ} \mathrm{C}$ for $15 \mathrm{~min}$, followed by chilling at $0{ }^{\circ} \mathrm{C}$ for 60 $\mathrm{min}$, and then held at each measuring temperature for 30 min prior to measurement. The chilling and holding of the sample were carried out in pre-equilibrated thermostatic glycol-containing baths, accurate to 0.1 ${ }^{\circ} \mathrm{C}$. SFC measurements were taken at $5{ }^{\circ} \mathrm{C}$ intervals.

\subsubsection{Crystal morphology measured by PLM}

A CX41RF microscope (Olympus, Japan) equipped with a Linkam PE 94 temperature control system (Linkam, UK) and an E330 Zuiko Digital camera (Olympus, Japan) were used to probe the fat crystals of lauric fat blends. Palmitic fat blends were viewed under a polarized light microscope (Olympus, Model BH-2, Tokyo, Japan) attached to a video color leica camera (Leica Q500mc Qwin Vol 0.02, Leica Cambridge Ltd., Cambridge, UK).

One drop of completely melted sample was put on a microscope slide and immediately covered with a cover slip. After that, the slide was placed on a temperature-controlled metal plate set at $20{ }^{\circ} \mathrm{C}$ to allow the crystallization process. Samples were pictured at 400x magnification and then the images were processed by the bundled software.

\subsubsection{Crystal polymorphism by XRD}

The crystal polymorphic forms of the fat blends were determined by a Bruker diffractometer (D8 Advance) with $\mathrm{Cu}-\mathrm{K} \alpha$ radiation $(\lambda=1.54056 \AA$, at $40 \mathrm{KV}$ and $40 \mathrm{~mA}$ ). The samples were scanned from 15 to $25^{\circ}$ ( 20 scale) with a $0.025^{\circ}$ step size. Polymorphic forms of the crystal were then identified from its short spacings. The $\beta^{\prime}$ form is characterized by two strong diffraction lines at 4.2 and $3.8 \AA$. Meanwhile, the $\beta$ form is characterized by a prominent diffraction line at $4.6 \AA$ in addition to less intense lines at 3.8 and $3.7 \AA$. The contents of $\beta^{\prime}$ and $\beta$ crystal in the fat blends were estimated by the 
relative intensity of the diffraction line either at 4.2 or $4.6 \AA$ A (Szydłowska-Czerniak et al., 2005).

For X-ray diffraction (XRD) analysis, the samples were melted at $90^{\circ} \mathrm{C}$ for 10 min to erase any crystal memory and then isothermally solidified in a thermostatic cabinet at $20 \pm 1^{\circ} \mathrm{C}$ for $24 \mathrm{~h}$ to allow a complete crystallization. The XRD machine was set and kept constant at $20^{\circ} \mathrm{C}$ during measurement and there was a 15 min interval approximately for each measurement.

\subsubsection{Statistical analysis}

In all analyses, three replicates were used and the results were expressed as mean value \pm standard deviation (SD). Statistical analyses of the obtained data were calculated using SPSS 12.0 software (SPSS Inc., Chicago, USA) and significant differences between means were determined at a $95 \%$ confidence interval $(P<0.05)$. For SFC results, standard deviation bars were plotted in the figures.

\section{RESULTS AND DISCUSSION}

\subsection{Calculation procedure}

Fat blends for fat-rich foods are commonly prepared from different sources of vegetable fats and oils. A combination of them, instead of a single source, will generally be the only way to cover a wide range of plasticity as required by different types of fat-rich products. Depending on the desired product plasticity, two or more fats/oils are mixed at certain ratios to obtain the requested fat blend composition. It is a common practice that fat blends are prepared based on the weight ratio of the starting fats and oils. Unfortunately, a trial and error method is often becoming an inevitable part of this procedure in order to get the appropriate fat to oil ratio. On the other hand, it has been acknowledged that TAGs are the major components in fats/oils and play a crucial role in determining the final products' properties. Each TAG species has a distinct melting point that correlates to certain key properties. Whenever the TAG composition of the initial fats and oils is known, there will be a possibility of clustering them into several groups to give a meaningful interpretation. A calculation procedure described below was developed to eliminate the drawbacks of the previous methods by placing emphasis on the different clusters of TAG present in the fat system based on their melting points.

\subsubsection{Selection of the starting fats and oils}

There are different sorts of edible fats and oils that are produced by manufacturers. The decision for choosing the starting fats and oils relies on several conditions and one of the main considerations is how to balance the availability over the cost (Wiedermann, 1968; Smallwood, 1989; Block et al., 1997; L'Abbé et al., 2009). This means, to a certain point, that some raw materials may be replaced in order to get similar product properties. Their chemical composition, specifically the TAG distribution, is the most important criteria for the selection of these starting fats and oils.

Refined, Bleached and Deodorized (RBD) fats and oils are the processed products that are commonly found in the market. In addition, several well-established technologies such as fractionation, hydrogenation and interesterification (both chemical and enzymatic) could also produce new products of fats and oils with unique physicochemical properties in the industry. Those modified fats and oils commonly possess a completely different TAG distribution compared to their original forms. RBD palm oil, for example, can be transformed using fractional crystallization techniques into less saturated fractions such as palm olein and superolein at the expense of more saturated fractions namely palm stearin and palm mid fraction (Kellens et al., 2007). Rapeseed oil, containing mostly unsaturated fatty acids, (Linoleic and Oleic acids) can be fully hydrogenated into a high melting fat with Stearic acid as the main saturated fatty acid.

Both natural and modified vegetable fats and oils are usually mixed in order to have wide ranges of product visco-elasticity. To obtain a good quality of visco-elastic products, there should be present an appropriate ratio of high and low melting TAG fractions in the fat blends. It is acknowledged that those TAG melting points are directly affected by their chemical structures namely the carbon chain length and the degree of unsaturation. The shorter the carbon chain length and the higher the unsaturation degree, the lower of the TAG melting points will be (Dijkstra, 2008). In this research, lauric and palmitic blends were chosen as the model of fat system where the former represents medium-chain TAG blends and the later demonstrates long-chain TAG blends.

All fat blends were also formulated as a ternary mixture where the initial fats and oils are either rich in high, medium or low melting fractions. A ternary blend was used as it may give a flexible blending calculation to reach certain ratios of any fraction in the system by adjusting the amount of initial samples. As shown in Table 1, HOSO and SBO were selected to represent the low melting fraction having a high unsaturation degree. HOSO had $92.33 \%$ TAG with 3 DB while SBO was mainly composed of TAGs with 3, 4 and 5 or more DB $(12.87,25.48$ and $58.67 \%$, respectively). In the meantime, PKO and $\mathrm{POO}$ were chosen for the medium melting fraction. Instead of a highly saturate fat $(93.14 \%$ TAGs fully saturated), PKO melts at a middle temperature as its fatty acids are mostly of medium carbon 
TABLE 1. Quality parameters of the fats and oils

\begin{tabular}{lcccccc}
\hline & \multicolumn{5}{c}{ Raw materials $^{\text {a) }}$} \\
\cline { 2 - 7 } Parameters & HOSO & PKO & POS $^{\mathbf{2}}$ & SBO & POO & POS $^{\mathbf{1}}$ \\
\hline IV & $90.5 \pm 0.8$ & $16.4 \pm 0.4$ & $12.1 \pm 0.4$ & $135.7 \pm 0.6$ & $61.9 \pm 0.6$ & $27.0 \pm 0.2$ \\
FFA (\%) & $0.06 \pm 0.00$ & $0.11 \pm 0.01$ & $0.09 \pm 0.00$ & $0.05 \pm 0.00$ & $0.11 \pm 0.02$ & $0.12 \pm 0.02$ \\
PV (meq.O $/$ /kg) & $0.60 \pm 0.07$ & $0.72 \pm 0.08$ & $0.45 \pm 0.03$ & $0.71 \pm 0.06$ & $0.16 \pm 0.03$ & $0.35 \pm 0.02$ \\
AV & $0.94 \pm 0.01$ & $1.58 \pm 0.12$ & $1.36 \pm 0.14$ & $0.74 \pm 0.06$ & $1.97 \pm 0.08$ & $1.74 \pm 0.08$ \\
Unsaturation degree of & & & & & & \\
triglyceride ${ }^{b)}$ & - & $93.14 \pm 0.01$ & $96.41 \pm 1.31$ & - & $1.70 \pm 0.08$ & $41.61 \pm 1.84$ \\
Saturated & - & $5.22 \pm 0.11$ & $2.94 \pm 1.11$ & $0.45 \pm 0.02$ & $36.14 \pm 0.94$ & $38.17 \pm 0.97$ \\
1 DB & $6.51 \pm 0.56$ & $1.64 \pm 0.12$ & $0.65 \pm 0.20$ & $2.53 \pm 0.21$ & $48.79 \pm 0.76$ & $15.42 \pm 0.94$ \\
2 DB & $92.33 \pm 0.58$ & - & - & $12.87 \pm 0.64$ & $12.86 \pm 0.14$ & $4.80 \pm 0.39$ \\
3 DB & $1.12 \pm 0.02$ & - & - & $25.48 \pm 0.76$ & $0.51 \pm 0.04$ & - \\
4 DB & - & - & - & $58.67 \pm 1.12$ & - & - \\
5 DB and more & - & & & &
\end{tabular}

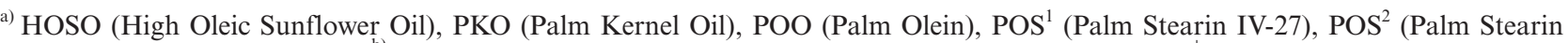
IV-12) and SBO (Soybean Oil); ${ }^{b} \mathrm{DB}$ (number of double bonds in triacylglycerols) as measured by $\mathrm{Ag}^{+} \mathrm{HPLC}_{\text {. }}$

chain length. Meanwhile, Palm Olein also melts at a middle temperature as it has a combination of long carbon chain length and an approximately equal of unsaturation/saturation degree. Palm Stearin having IV 12 and 27 were provided to enhance the high melting fraction of the fat blends. A lower IV indicates less double bounds in the PS thus a higher melting point. PS with IV 12 had $96.41 \%$ fully saturated TAGs and that of IV 27 was mainly composed of $41.61 \%$ fully saturated TAGs and $38.17 \%$ TAGs of $1 \mathrm{DB}$.

The quality of raw materials is another important parameter that should be taken into account. Minor substances commonly found in the fats and oils are free fatty acids (FFA), monoacylglycerols (MAG), diacylglycerols (DAG) and phospholipids (Talbot et al., 2012). In addition, fat oxidation induced by improper heat treatment and storage may result in primary and secondary oxidation products such as hydroperoxides, ketons and aldehydes (Frankel, 1991). These minor substances and products of fat oxidation may significantly alter the physicochemical properties of the fat blends.

The standard parameters for a special quality grade of crude palm oil, for example, are as follows: FFA (2.5\%), PV (2.0 meq $\left.\mathrm{O}_{2} / \mathrm{kg}\right)$ and AV (4.0) (MS-814, 2007). FFA value is used to quantify the amount of free fatty acid as a result of TAG hydrolytic breakdown. Meanwhile, PV is used to measure the primary oxidation products. $\mathrm{AV}$, on the other hand, is used to determine the secondary oxidation products, primarily 2 -alkene present in the samples (Gibon et al., 2007; Mohammadi et al., 2012). The low values indicate that a good raw material is used to produce the oil and subsequently the product is appropriately being stored and transported. It is then being assumed that the presence of those detrimental components is minimal. Table 1 showed that all starting fats and oils in this investigation had good quality. Their FFA, PV and AV were within the intervals of commercial standards and the values were significantly low. Therefore, it could be assumed that minor substances and products of fat oxidation had an insignificant influence on the developed fat systems.

\subsubsection{Grouping TAG based on the melting point}

Vegetable fats and oils consist mostly of TAG mixtures and as consequence they have melting point intervals. In a simple case, a pure TAG has a very sharp melting point. Even so, as fat is known for having polymorphism, a single TAG may have more than one melting point depending on the type of crystal formed. The common types of crystal found in vegetable fats listed from less stable to the most stable polymorph are alpha $(\alpha)$, beta prime $\left(\beta^{\prime}\right)$ and beta $(\beta)$ (Himawan et al., 2006). In the calculation procedure, a table consisting of a series of TAGs commonly found in vegetable fats and oils is prepared following the increment in their melting points. The data of individual TAG melting point is obtained from previous references. As polymorphism is evident in fat crystals, only the melting point of beta prime crystal is selected for this sorting purpose in order to get an equal comparison.

The list of TAGs was then divided into four groups to indicate their physical states at chilled, room, body and heated temperatures. Triglycerides in the chilled-melting TAG (C) group completely melt under cool conditions (below $5{ }^{\circ} \mathrm{C}$ ) while those in the room-melting TAG (R) group melt at ambient temperatures or higher (between 5 and $25^{\circ} \mathrm{C}$ ). Triglycerides in the body-melting TAG (B) group 
melt near body temperature (between 25 and $45^{\circ} \mathrm{C}$ ). Lastly, in the heated-melting TAG $(\mathrm{H})$ group, triglycerides only melt at higher temperatures than those of other groups (above $45^{\circ} \mathrm{C}$ ). The significance of TAG grouping is that those melting attributes of TAGs can directly be correlated to certain functional properties of the fat blends (O'Brien, 2008).

The list of TAGs used in the formulation of lauric and palmitic fat blends is presented in Table 2 and Table 3, respectively. It was shown that the combination of fatty acid species (chain length, degree of unsaturation) and their distribution on the TAG backbone might dictate their melting point and therefore, their position in the groups. In this research, the emphasis was placed on the B-group and $\mathrm{H}$-group since TAGs from both groups will directly influence the visco-elastic properties of the fat blends. If the high melting fraction is present in an excessive amount, it may give undesired oral properties such as graininess or waxiness. However, if the amount of solid fraction is not sufficient, the product may become soft or, in fact a separation of the liquid fraction from the solid part is inevitable. Thus, both groups were set as the variables for the fat blend formulation in this calculation procedure.

It was clearly shown that the $\mathrm{H}$ group of lauric and palmitic fat blends consisted mainly of tri-saturated TAGs and PPP was the major TAG in both the blends. However, the other solid fraction in the B group was completely different in terms of TAGs species between these two blends. In the B group, lauric fat blends were composed mainly of LaLaLa, LaLaM, CLaLa and LaMM while the palmitic fat blend had POP, POS and PPL as its major TAGs. It was known that a similar formulation could have different TAG composition. Therefore, the main

TABLE 2. Triacylglycerol distribution of formulated lauric fat blends

\begin{tabular}{|c|c|c|c|c|c|c|c|}
\hline \multirow[b]{2}{*}{ Group $^{\text {a) }}$} & \multirow[b]{2}{*}{ TAG $^{\text {b) }}$} & \multicolumn{3}{|c|}{ Starting oil (\%) } & \multicolumn{3}{|c|}{ Lauric fat blend $(\%)^{c)}$} \\
\hline & & HOSO & PKO & POS $^{2}$ & BH50H5 & BH50H10 & BH50H15 \\
\hline chilled & OLL & 0.54 & - & - & 0.25 & 0.25 & 0.25 \\
\hline chilled & OOL & 2.55 & - & - & 1.17 & 1.18 & 1.19 \\
\hline chilled & OOO & 87.99 & - & 1.14 & 40.49 & 40.81 & 41.13 \\
\hline chilled & POL & - & - & 0.27 & 0.01 & 0.03 & 0.05 \\
\hline room & $\mathrm{LaOO}$ & - & 1.37 & - & 0.68 & 0.59 & 0.50 \\
\hline room & POO & 5.24 & - & 1.50 & 2.47 & 2.58 & 2.69 \\
\hline room & $\mathrm{LaLaO}$ & - & 3.12 & - & 1.56 & 1.35 & 1.14 \\
\hline room & SOO & 3.00 & - & 0.43 & 1.40 & 1.43 & 1.47 \\
\hline room & LaMO & - & 2.78 & - & 1.39 & 1.20 & 1.01 \\
\hline room & MLP & 0.68 & - & - & 0.31 & 0.31 & 0.32 \\
\hline room & PPL & - & - & 0.50 & 0.02 & 0.05 & 0.09 \\
\hline body & CCLa & - & 7.70 & - & 3.85 & 3.32 & 2.80 \\
\hline body & MPO & - & 0.44 & - & 0.22 & 0.19 & 0.16 \\
\hline body & $\mathrm{LaPO}$ & - & 2.55 & - & 1.27 & 1.10 & 0.93 \\
\hline body & CLaLa & - & 9.78 & - & 4.89 & 4.22 & 3.56 \\
\hline body & POP & - & - & 9.38 & 0.38 & 0.99 & 1.60 \\
\hline body & LaLaLa & - & 37.34 & - & 18.66 & 16.12 & 13.58 \\
\hline body & LaLaM & - & 21.98 & - & 10.95 & 9.46 & 7.97 \\
\hline body & POS & - & - & 6.37 & 0.26 & 0.67 & 1.09 \\
\hline body & LaMM & - & 8.91 & - & 4.45 & 3.85 & 3.24 \\
\hline heated & LaMP & - & 2.68 & - & 1.34 & 1.16 & 0.97 \\
\hline heated & PLaP & - & 0.93 & - & 0.46 & 0.40 & 0.34 \\
\hline heated & PPP & - & - & 80.41 & 3.26 & 8.51 & 13.75 \\
\hline$[\mathrm{C}]$ & & 91.08 & - & 1.41 & 41.92 & 42.27 & 42.61 \\
\hline$[\mathrm{R}]$ & & 8.92 & 7.27 & 2.43 & 7.83 & 7.52 & 7.21 \\
\hline [B] & (lotal) & - & 88.70 & 15.75 & 44.93 & 39.93 & 34.94 \\
\hline$[\mathrm{H}]$ & & - & 3.61 & 80.41 & 5.07 & 10.07 & 15.06 \\
\hline
\end{tabular}

a) Grouping of triacylglycerols based on melting point: chilled/C, room/R, body/B and heated/H. ${ }^{\text {b) }}$ Arranged fatty acid $C$ capric, $L a$ lauirc, $M$ myristic, $P$ palmitic, $S$ stearic, $O$ oleic, $L$ linoleic. ${ }^{c)}$ BH50: total body and heated group TAG set at $50 \%$ for all blends. H5/10/15: heated group TAG adjusted at 5, 10 and $15 \%$ respectively. The calculated values were reported for the blends. 
TABLE 3. Triacylglycerol distribution of formulated palmitic fat blends

\begin{tabular}{|c|c|c|c|c|c|c|c|}
\hline \multirow[b]{2}{*}{ Group $^{\text {a) }}$} & \multirow[b]{2}{*}{ TAG $^{\text {b) }}$} & \multicolumn{3}{|c|}{ Starting oil (\%) } & \multicolumn{3}{|c|}{ Palmitic fat blend $(\%)^{c)}$} \\
\hline & & SBO & POO & POS $^{1}$ & BH50H5 & BH50H10 & BH50H15 \\
\hline chilled & LnLnLn & 7.67 & - & - & 0.02 & 0.83 & 1.62 \\
\hline chilled & LnLLn & 1.28 & - & - & - & 0.14 & 0.27 \\
\hline chilled & LLL & 23.57 & - & - & 0.06 & 2.54 & 4.96 \\
\hline chilled & OLL & 17.92 & - & - & 0.05 & 1.93 & 3.77 \\
\hline chilled & OOL & 8.99 & 0.66 & 0.31 & 0.66 & 1.48 & 2.29 \\
\hline chilled & OOO & 1.93 & 4.44 & 2.04 & 4.26 & 3.64 & 3.04 \\
\hline chilled & LnPL & 3.56 & - & - & 0.01 & 0.38 & 0.75 \\
\hline chilled & LnOP & 15.86 & - & - & 0.04 & 1.71 & 3.34 \\
\hline chilled & POL & 13.64 & 11.82 & 4.16 & 11.27 & 10.34 & 9.42 \\
\hline chilled & SLL & 0.15 & - & - & - & 0.02 & 0.03 \\
\hline room & POO & 1.12 & 29.21 & 12.27 & 27.91 & 22.48 & 17.14 \\
\hline room & SOO & 0.70 & 3.18 & 0.85 & 3.01 & 2.40 & 1.81 \\
\hline room & MLP & - & 2.81 & 0.62 & 2.64 & 2.03 & 1.42 \\
\hline body & PPL & 2.25 & 10.79 & 4.68 & 10.33 & 8.53 & 6.77 \\
\hline body & POP & 0.60 & 29.23 & 31.64 & 29.33 & 26.68 & 24.07 \\
\hline body & PSO & 0.30 & 5.37 & 4.23 & 5.27 & 4.57 & 3.89 \\
\hline body & SOS & - & - & 0.60 & 0.04 & 0.13 & 0.22 \\
\hline heated & МMM & - & 0.51 & 0.08 & 0.48 & 0.36 & 0.25 \\
\hline heated & MMP & - & 1.91 & 0.70 & 1.82 & 1.44 & 1.07 \\
\hline heated & MPM & - & - & 2.39 & 0.17 & 0.52 & 0.87 \\
\hline heated & PPP & - & - & 29.78 & 2.15 & 6.52 & 10.82 \\
\hline heated & SPP & - & - & 5.64 & 0.41 & 1.24 & 2.05 \\
\hline$[\mathrm{C}]$ & (Total) & 94.57 & 16.92 & 6.51 & 16.37 & 22.99 & 29.49 \\
\hline$[\mathrm{R}]$ & & 1.82 & 35.20 & 13.74 & 33.56 & 26.91 & 20.37 \\
\hline [B] & & 3.15 & 45.39 & 41.15 & 44.97 & 39.92 & 34.95 \\
\hline$[\mathrm{H}]$ & & - & 2.42 & 38.59 & 5.03 & 10.08 & 15.05 \\
\hline
\end{tabular}

a) Grouping of triacylglycerols based on melting point: chilled/C, room/R, body/B and heated/H. ${ }^{\text {b) }}$ Arranged fatty acid $M$ myristic, $P$ palmitic, $S$ stearic, $O$ oleic, $L$ linoleic, $L n$ Linolenic. ${ }^{c)}$ BH50: total body and heated group TAG set at $50 \%$ for all blends. H5/10/15: heated group TAG adjusted at 5,10 and $15 \%$, respectively. The calculated values were reported for the blends.

advantage of the presented procedure was to have a deeper insight into the physicochemical properties of the prepared fat blends. It may show the TAG species composition and distribution, unsaturation level, amount of solid fraction, polymorphic tendency and fat incompatibility, to some degree.

\subsubsection{Calculation of the formula using linear interpolation}

The desired TAG distribution of the fat blend should firstly be determined. There were two variables in the calculation procedure that aims to modify the TAG composition of the final fat blend. The amount of $\mathrm{H}$ and $\mathrm{BH}$ groups were those two factors that could be varied using the given calculation. For example, in this research, both lauric and palmitic fat blends were set to have $50 \%$ TAGs from both $\mathrm{B}$ and $\mathrm{H}$ groups while TAGs from the $\mathrm{H}$ group were varied at 5, 10 and $15 \%$. To obtain those formulated blends, a calculation procedure was developed as demonstrated in Figure 1 where a ternary mixture was prepared by blending the raw materials in two stages.

In the first stage, high meting fat $(\mathrm{X})$ was mixed with medium melting fat (Y) to obtain the first blend with a definitive $R_{m}$ ratio. The $R_{m}$ was a ratio of the heated-melting TAG group $\left(\mathrm{H}_{\mathrm{m}}\right)$ to the sum of heated $\left(\mathrm{H}_{\mathrm{m}}\right)$ and body $\left(\mathrm{B}_{\mathrm{m}}\right)$ melting TAG groups presented in the final fat blend $(\mathrm{M})$ as defined by Eq. (1). The $\mathrm{R}$ ratio of vegetable fats and oils was found to be unique and different from one to the others depending mainly on their saturation degree.

$$
\begin{aligned}
& R_{m}=H_{m} /\left(B_{m}+H_{m}\right) \\
& U_{r m}=U_{0}+\left(U_{1}-U_{0}\right) \frac{R_{m}-R_{u 0}}{R_{u 1}-R_{u 0}}
\end{aligned}
$$




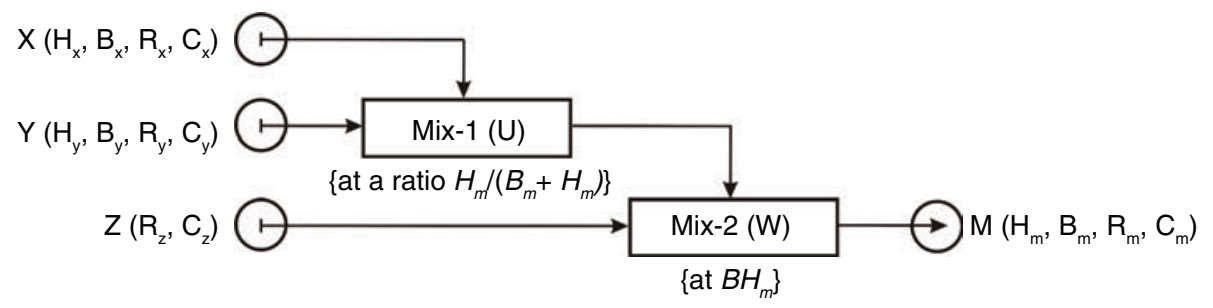

FIGURE 1. A model of ternary blending process based on melting TAG groups. Definition of the symbols was given in Nomenclature.

As the $\mathrm{R}_{\mathrm{m}}$ value was defined while both $\mathrm{R}_{\text {ио }}$ and $\mathrm{R}_{\mathrm{u} 1}$ (two arbitrary values of $\mathrm{R}$ in the first blend) were known from the initial samples, the $\mathrm{U}_{\mathrm{rm}}$ (ratio of high to medium melting fat) having an $\mathrm{R}_{\mathrm{m}}$ ratio can then be calculated. The simplest way to calculate the unknown value as if it lied on a straight line between the two known values was using linear interpolation. The formula for this calculation procedure was then given by equation 2 . Whenever the value of $U_{r m}$ was obtained, the required amount of high (X) and medium (Y) melting fats in the fat blend could be established.

In the second stage, the first blend was further mixed with liquid oil (Z) to get the final blend (M). This liquid oil generally contains triglycerides only from room and chilled melting TAG groups. Thus, in the second blend, the liquid oil has a function to dilute the first blend until the required amount of $\mathrm{B}_{\mathrm{m}}$ and $\mathrm{H}_{\mathrm{m}}$ is achieved in the final blend. As this calculation procedure aimed to set the amount of $\mathrm{B}$ and $\mathrm{H}$ groups, the $\mathrm{BH}_{\mathrm{m}}$ was then used as a known parameter (Eq. (3)) for the further calculation.

$B H_{m}=\left(B_{m}+H_{m}\right)$

$W_{b h}=W_{0}+\left(W_{1}-W_{0}\right) \frac{B H_{m}-B H_{w 0}}{B H_{w 1}-B H_{w 0}}$

Using a similar approach, the $\mathrm{W}_{\mathrm{bh}}$ (ratio of first blend to liquid oil) at a definitive $\mathrm{BH}_{\mathrm{m}}$ value can then be calculated as the value of $\mathrm{BH}_{\mathrm{m}}$ was predetermined while the values of both $\mathrm{BH}_{\mathrm{wo}}$ and $\mathrm{BH}_{\mathrm{w} 1}$ (two arbitrary values of $\mathrm{BH}$ in the second blend) were known from the first blend and the liquid oil. To perform the calculation, the second linear interpolation was run and the formula was given by equation 4 . When the value of $\mathrm{W}_{\mathrm{bh}}$ was obtained, the required amount of liquid oil in the fat blend could be established. This step finalized the calculation procedure where the amount of all raw materials (X, Y and Z) could eventually be obtained for the given formulated fat blend. Tables 2 and 3 show the results of the calculations for the formulation of lauric and palmitic fat blends. It can be seen that TAG distribution had already changed by following the given formula. A formulation of $\mathrm{BH} 50 \mathrm{H} 15$, for example, indicated that the fat blend consisted of $50 \%$ TAGs from the combination of $\mathrm{B} / \mathrm{H}$ groups in which $15 \%$ TAGs came from $\mathrm{H}$ group (thus, B group had $35 \%$ TAGs). The remaining $50 \%$ of TAGs in the formulation then came from a combination of $\mathrm{C} / \mathrm{R}$ groups.

It is worth mentioning that this calculation procedure has a limitation when the desired fat blend composition (denoted by $\mathrm{R}$ value) lied outside the range of starting fats/oils. In addition, if the liquid oil contains some high or medium melting fractions (B or $\mathrm{H}$ groups), some adjustments on the calculations need to be performed.

A customized spreadsheet template for performing fat blend calculations has been created under Microsoft Excel ${ }^{\mathrm{TM}}$ program. A copy of the calculation template can be acquired from the author.

\subsection{Influence on DSC crystallization properties}

The given calculation procedure could be exploited to prepare fat blends where TAGs from body and heated melting TAG groups could be adjusted to the desired values. From the DSC thermogram of lauric fat blends as shown in Figure 2, it was observed that some adjustments to the TAG groups produced noted effects. In general, there were three main peaks on the crystallization thermogram representing high, medium and low melting fractions. When the amount of $\mathrm{BH}$ group was kept constant at $50 \%$, the increments of $\mathrm{H}$ ratio $(5,10$ and $15 \%$ ) were followed by decreases in B ratio ( 45 , 40 and $35 \%$, respectively) in the fat blends. Higher $\mathrm{H}$ ratios implied higher amounts of high melting fraction in the fat blend and, as a result, the crystallization peaks at the higher temperature region became larger $\left(c_{1}, b_{1}, a_{1}\right.$, respectively). In addition, their peak-maximum were shown to be significantly shifted as the effect of depressed TAG melting point influenced by fat solubility played a role. At the same time, as B ratios were becoming lower, the crystallization peaks at the middle temperature region also became smaller $\left(c_{2}, b_{2}, a_{2}\right.$, respectively). Finally, it was found that the crystallization peaks at the lower temperature region $\left(\mathrm{a}_{3}, \mathrm{~b}_{3}\right.$ and $\left.\mathrm{c}_{3}\right)$ remained similar since the amount of chilled and body melting TAG groups was unaltered. 
For palmitic fat blends, it was observed that there were only two peaks representing high $\left(\mathrm{d}_{1}, \mathrm{e}_{1}\right.$ and $\left.\mathrm{f}_{1}\right)$ and medium $\left(\mathrm{d}_{2}, \mathrm{e}_{2}\right.$ and $\left.\mathrm{f}_{2}\right)$ melting fractions. As there was a limitation on the instrument for measuring at very low temperature (cut off $-60{ }^{\circ} \mathrm{C}$ ), the peak of low melting fraction did not appear. The low melting fraction of palmitic fat blends had more double bonds compared to that of lauric fat blends (Table 2 and Table 3). Therefore, its peak was supposed to appear at a lower temperature. Nevertheless, the crystallization peaks of high and medium melting fractions were comparable between these two blends. Hence, no further discussion about the crystallization peaks of palmitic fat blends is given.

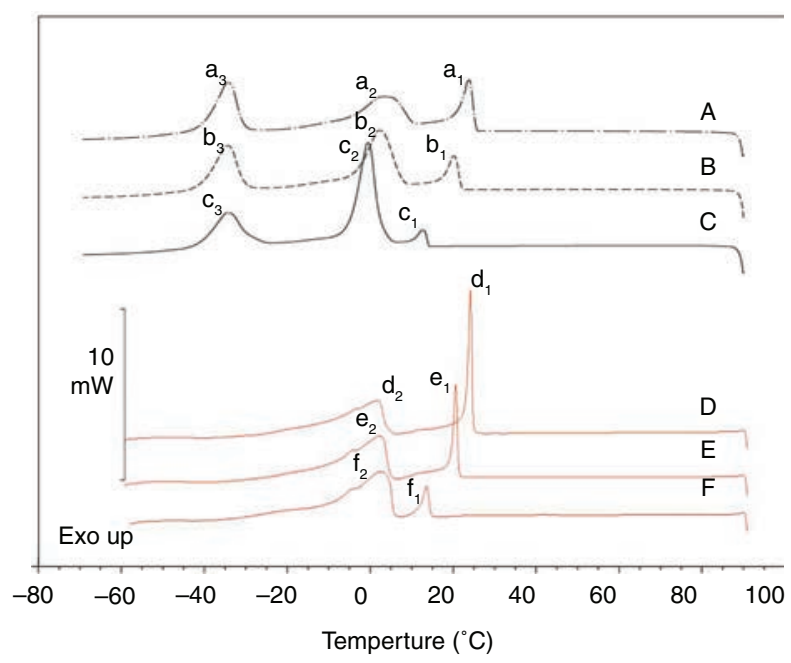

FIgURE 2. DSC cooling thermogram of lauric and palmitic fat blends at $\mathrm{BH} 50 \mathrm{H} 15$ (A and D), $\mathrm{BH} 50 \mathrm{H} 10$ (B and E) and $\mathrm{BH} 50 \mathrm{H} 5$ (C and $\mathrm{F}$, respectively).

\subsection{Influence on solid fat content/SFC profile}

Different formulations of lauric and palmitic fat blends based on TAG group resulted in the distinct patterns of SFC curves as shown in Figure 3. For both lauric and palmitic blends, higher amounts of $\mathrm{H}$ group gave significantly $(P<0.05)$ higher SFC values at $20{ }^{\circ} \mathrm{C}$ and beyond. As more solid fat was available from the increments of $\mathrm{H}$ group, the slopes of the SFC curve also became steeper. In addition, both fat blends were completely melted $(\mathrm{SFC}=0 \%)$ at higher temperatures $(\mathrm{BH} 50 \mathrm{H} 5$ blends at $40{ }^{\circ} \mathrm{C}$ while $\mathrm{BH} 50 \mathrm{H} 10$ blends at $50{ }^{\circ} \mathrm{C}$ ). These results were found to be comparable with the DSC thermal properties.

On the other hand, when the amount of $\mathrm{BH}$ group was fixed at $50 \%$, the SFC values at the temperature below $20{ }^{\circ} \mathrm{C}$ were not significantly different $(P<0.05)$ within the same group of fat blends (either lauric or palmitic blend). The amount of solid fat at this temperature range was a sum of those from the $\mathrm{H}$ group (which crystallized first) and B group (incorporated later followed by further cooling) where the value was set constant at BH50. Thus, it was expected that the amount of solid fraction would not significantly differ. In general, however, it was observed that the SFC values of palmitic fat blends were generally higher than those of lauric fat blends at any measuring temperatures for the same formulation. The differences in the TAG compositions, where lauric blends were composed mainly by LaLaLa, LaLaM, CLaLa and LaMM (Table 2) and palmitic blends consisted mostly of POP, PPL and PSO (Table 3), were considered the main influencing factors.

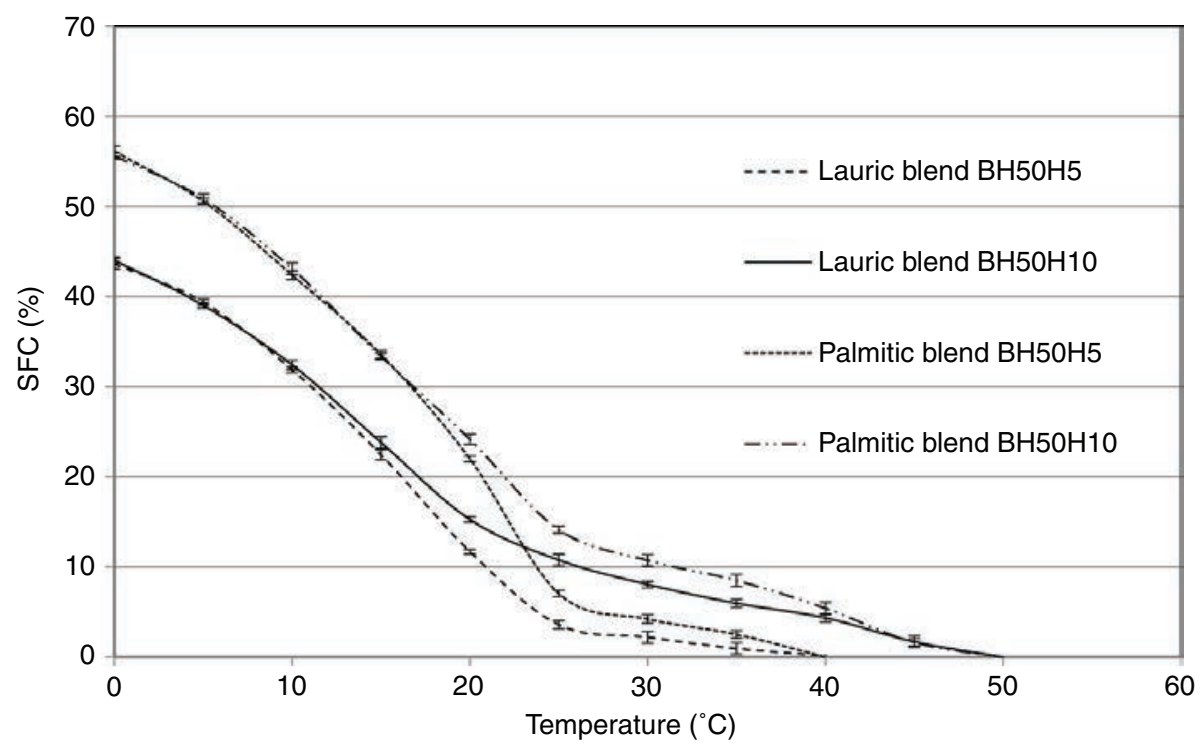

FIGURE 3. SFC of lauric and palmitic fat blends. Values were means with their standard deviations of triplicate analyses. 


\subsection{Photomicrographs of the fat crystal by PLM}

In order to evaluate the influences of melting TAG formulations on the network structure of fat crystala in terms of crystal density, crystal morphology and crystal size; the microstructure of lauric and palmitic fat blends, formulated at $\mathrm{BH} 50$ and $\mathrm{H} 5 / 10 / 15$, were visualized by PLM. Figure 4 shows that both lauric (b) and palmitic (d) fat blends having $\mathrm{BH} 50 \mathrm{H} 10$ formulation contained crystals in the form of small needle-shaped like crystals with less space among adjacent crystals. Other formulations ( $\mathrm{BH} 50 \mathrm{H} 5$ and $\mathrm{BH} 50 \mathrm{H} 15)$ also showed similar crystal shapes. In addition, greater amounts of high melting fraction in all the fat blends resulted in higher crystal density. The $\mathrm{H} 15$ formulation was the densest and that of $\mathrm{H} 5$ was the least dense for both lauric and palmitic fat blends (unpublished data). Even though the formulated fat blends indicated comparable crystal morphology, those of the initial fat samples were found to be completely different. PKO (a) was characterized by a few big spheroidal clusters of smaller crystallites while PS-IV12 (c) resembled more dendritic spherulite crystals. Smaller size crystals can result in firmer products but larger size crystals can give an unwanted sandy mouth feel (Meng et al., 2011).

\subsection{Polymorphic behavior of the fat blends}

The XRD spectroscopy was used to characterize the TAG polymorphic form of fat blends in different formulations by determining the short spacings of the crystals. The diffractogram showed that the content of $\alpha$ polymorph was negligible in all the fat blends as they had already been stored for $24 \mathrm{~h}$. Meanwhile, the short spacing pattern of 4.2 and $3.8 \AA$ was found in all formulated palmitic fat blends as indicated in Table 4. Therefore, the predominant polymorph in palmitic fat blends was the $\beta$ ' crystal. It seemed that the larger amount of high melting fraction in the blends did not alter the crystal polymorph. Palm oil is indeed acknowledged for its crystal stability in $\beta$ ' (Lin, 2011). For lauric fat blends, a very strong short spacing at 4.6 $\AA$ and weaker bands at 3.8 and $3.7 \AA$ were observed in $\mathrm{BH} 50 \mathrm{H} 10$ and $\mathrm{BH} 50 \mathrm{H} 15$ formulations indicating the presence of $\beta$ crystals. However, lauric fat blends at a smaller amount of high melting fraction $(\mathrm{BH} 50 \mathrm{H} 5)$ had both $\beta$ ' and $\beta$ polymorphs. Lauric fat (i.e. PKO) is known to have a stable $\beta$, polymorphic form (Jin et al., 2008). However, the increased amount of $\beta$-tending TAG, such as PPP and POP (Meng et al., 2011), may alter the polymorphic form of the lauric fat blend. This result suggested that the larger amount of high melting (a)

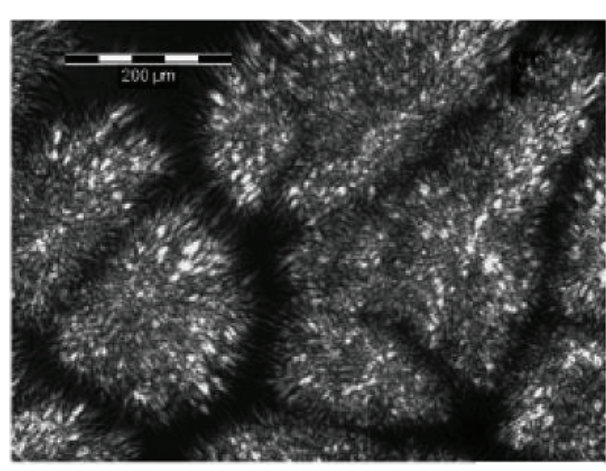

(c)

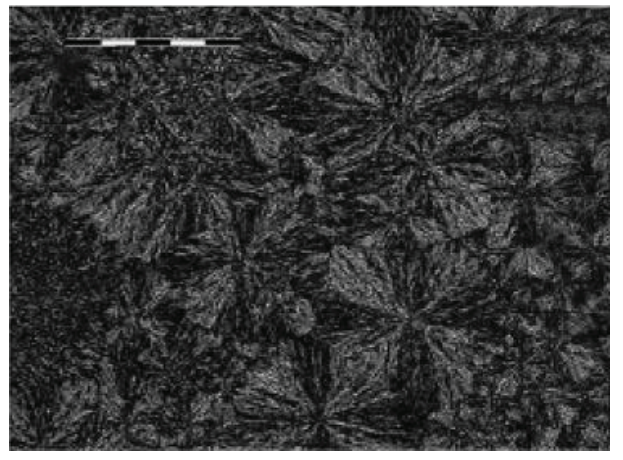

(b)

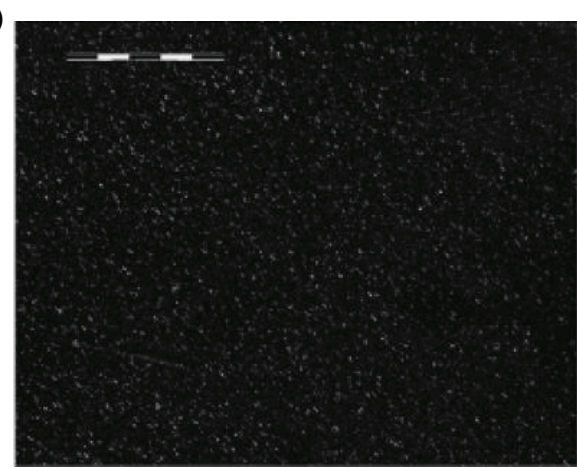

(d)

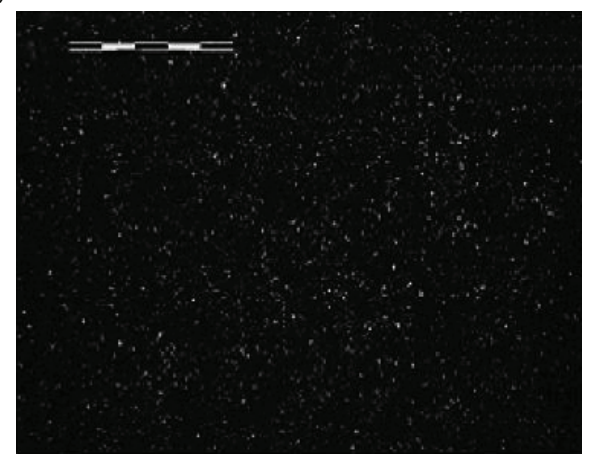

FIGURE 4. Pictomicrographs of PKO (a), POS IV-12 (c), lauric (b) and palmitic (d) fat blends formulated at BH50H10. 
TABLE 4. Polymorphic forms of the fat blends

\begin{tabular}{|c|c|c|c|c|c|}
\hline \multirow[b]{2}{*}{ Fat blend formulation ${ }^{\text {a) }}$} & \multirow[b]{2}{*}{ Polymorph } & \multicolumn{4}{|c|}{ XRD short spacing $\left(\AA{ }^{\mathfrak{b})}\right.$} \\
\hline & & 4.6 & 4.2 & 3.8 & 3.7 \\
\hline Lauric blend $\mathrm{BH} 50 \mathrm{H} 5$ & $\beta^{\prime}+\beta$ & $4.58(\mathrm{~s})$ & $4.24(\mathrm{~s})$ & $3.88(\mathrm{~m}), 3.81(\mathrm{~m})$ & $3.75(\mathrm{~m})$ \\
\hline Lauric blend $\mathrm{BH} 50 \mathrm{H} 10$ & $\beta$ & 4.58 (vs) & & $3.87(\mathrm{~s})$ & $3.74(\mathrm{~s})$ \\
\hline Lauric blend $\mathrm{BH} 50 \mathrm{H} 15$ & $\beta$ & 4.60 (vs) & & $3.88(\mathrm{~s})$ & $3.75(\mathrm{~s})$ \\
\hline Palmitic blend $\mathrm{BH} 50 \mathrm{H} 5$ & $\beta^{\prime}$ & & 4.20 (vs) & $3.81(\mathrm{~s})$ & \\
\hline Palmitic blend $\mathrm{BH} 50 \mathrm{H} 10$ & $\beta^{\prime}$ & & $4.18(\mathrm{vs})$ & $3.80(\mathrm{~s})$ & \\
\hline Palmitic blend $\mathrm{BH} 50 \mathrm{H} 15$ & $\beta^{\prime}$ & & 4.19 (vs) & $3.81(\mathrm{~s})$ & \\
\hline
\end{tabular}

a) $\mathrm{BH} 50$ : total body and heated group TAG set at 50\% for all blends. H5/10/15: heated group TAG adjusted at 5, 10 and $15 \%$ respectively.

b) m: medium, s: strong and vs: very strong.

fraction in lauric fat blends stabilized the crystal in $\beta$ polymorphic form.

\section{CONCLUSIONS}

A new calculation procedure to prepare lauric and palmitic fat blends based on the grouping TAG melting point was described in detail. The fat blends were formulated as a ternary mixture. In the given procedure, both adjustment of the $\mathrm{H}$ group and that of the $\mathrm{BH}$ group in the fat blends were made available. To determine the amount of all raw materials needed for the fat blends as defined in the formula, Linear Interpolation was included in the calculation. This procedure offered more flexibility to formulate fat blends that have desired solid fat fraction by predetermining both $\mathrm{B}$ and $\mathrm{H}$ groups. As the $\mathrm{H}$ group increased, higher SFCs were observed with comparable intervals. The DSC crystallization thermogram, crystal microstructure and polymorphic behavior also showed similar trends for either lauric or palmitic fat blends. Nevertheless, instead of similar formulations, the crystallization behavior of lauric and palmitic fat blends was found to be slightly different as affected by the different TAG species present in the fat system. This approach, in general, gave better prediction about both the physicochemical properties of the fat blends and eventually the functional attributes of the resulted fat-rich foods.

\section{REFERENCES}

Avramenko Y, Kraslawski A. 2008. Case based design: Applications in process engineering. Berlin: Springer.

Block J, Barrera-Arellano D, Figueiredo M, Gomide FAC. 1997. Blending process optimization into special fat formulation by neural networks. J. Am. Oil Chem. Soc. 74, 1537-1541. http://dx.doi.org/10.1007/s11746-997-0073-5

Dijkstra AJ. 2008. Controlling physical and chemical properties of fat blends through their triglyceride compositions. In: Dijkstra AJ, Hamilton RJ and Hamm W (Eds.) Trans fatty acids, Blackwell Publishing Ltd, Oxford. http://dx.doi. org/10.1002/9780470697658.ch5

Firestone D. 1998. Official methods and recommended practices of the aocs. 5 Edn.: American Oil Chemists' Society.

Frankel EN. 1991. Review. Recent advances in lipid oxidation. J. Sci. Food Agric. 54, 495-511. http://dx.doi.org/10.1002/ jsfa. 2740540402
Ghotra BS, Dyal SD, Narine SS. 2002. Lipid shortenings: A review. Food Res. Int. 35, 1015-1048. http://dx.doi. org/10.1016/s0963-9969(02)00163-1

Gibon V, De Greyt W, Kellens M. 2007. Palm oil refining. Eur. J. Lipid Sci. Technol. 109, 315-335. http://dx.doi.org/10.1002/ ejlt. 200600307

Himawan C, Starov VM, Stapley AGF. 2006. Thermodynamic and kinetic aspects of fat crystallization. Adv. Colloid Interface Sci. 122, 3-33. http://dx.doi.org/10.1016/j.cis.2006.06.016

Jin Q, Zhang T, Shan L, Liu Y, Wang X. 2008. Melting and solidification properties of palm kernel oil, tallow, and palm olein blends in the preparation of shortening. J. Am. Oil Chem. Soc. 85, 23-28. http://dx.doi.org/10.1007/s11746-007-1152-3

Kellens M, Gibon V, Hendrix M, De Greyt W. 2007. Palm oil fractionation. Eur. J. Lipid Sci. Technol. 109, 336-349. http://dx.doi.org/10.1002/ejlt.200600309

L'Abbé M, Stender S, Skeaff C. 2009. Approaches to removing trans fats from the food supply in industrialized and developing countries. Eur. J. Clin. Nutr. 63, S50-S67. http:// dx.doi.org/10.1038/ejen.2009.14

Lin SW. 2011. Palm oil. In: Gunstone FD (Ed.) Vegetable oils in food technology: Composition, properties and uses, Blackwell Publishing, Chichester, UK: pp: 25-58. http:// dx.doi.org/10.1002/9781444339925

Manaf YNA, Marikkar JMN, Musthafa S, Saari MM. 2014. Composition and thermal analysis of binary mixtures of mee fat and palm stearin. J. Oleo Sci. 63, 325-332. http:// dx.doi.org/10.5650/jos.ess 13193

Meng Z, Liu Y-F, Jin Q-Z, Huang J-H, Song Z-H, Wang F-Y, Wang X-G. 2011. Comparative analysis of lipid composition and thermal, polymorphic, and crystallization behaviors of granular crystals formed in beef tallow and palm oil. J. Agric. Food Chem. 59, 1432-1441. http://dx.doi.org/10.1021/jf103875f

Meng Z, Liu Y, Shan L, Jin Q, Wang F, Wang X. 2011. Specialty fats from beef tallow and canola oil: Establishment of reaction conditions, characterization of products, and evaluation of crystal stability. Food Biophys. 6, 115-126. http://dx.doi.org/10.1007/s11483-010-9186-8

Mohammadi ZB, Maghsoudlou Y, Safafar H, Mahoonak ARS. 2012. Physicochemical properties and stability of oil extracted from three canola cultivars grown in Golestan province of Iran. J. Agric. Sci. Technol. 14, 577-586.

MS-814. 2007. Palm oil - specification (second revision). In: Malaysian Standard, SIRIM Berhad, Selangor Darul Ehsan: pp: 5 .

Nusantoro BP, Xanthina M, Kadivar S, Yanty NAM, Dewettinck K. 2016. Enzymatic interesterification of lauric fat blends formulated by grouping triacylglycerol melting points. J. Am. Oil Chem. Soc. 93, 1051-1062. http:// dx.doi.org/10.1007/s11746-016-2851-4

O'Brien RD. 2008. Fats and oils: Formulating and processing for applications. 3 Edn., Boca Raton: CRC press. http://dx.doi. org/10.1201/9781420061673

O'Brien RD, Jones LA, King CC, Wakelyn PJ, Wan PJ. 2005. Cottonseed oil. Bailey's industrial oil and fat products, John Wiley \& Sons, Inc. http://dx.doi.org/10.1002/047167849X. bio022 
12 • B.P. Nusantoro, N.A.M. Yanty, D. Van de Walle, C. Hidayat, S. Danthine and K. Dewettinck

Podmore J. 2008. Food applications of trans fatty acids. In: Dijkstra AJ, Hamilton RJ and Hamm W (Eds.) Trans fatty acids, Blackwell Publishing Ltd, Oxford. http://dx.doi. org/10.1002/9780470697658

Rombaut R, De Clercq N, Foubert I, Dewettinck K. 2009. Triacylglycerol analysis of fats and oils by evaporative light scattering detection. J. Am. Oil Chem. Soc. 86, 19-25. http://dx.doi.org/10.1007/s11746-008-1316-9

Smallwood N. 1989. Using computers for oil blending. J. Am. Oil Chem. Soc. 66. http://dx.doi.org/10.1007/bf02669943
Szydłowska-Czerniak A, Karlovits G, Lach M, Szłyk E. 2005. $\mathrm{X}$-ray diffraction and differential scanning calorimetry studies of $\beta^{\prime} \rightarrow \beta$ transitions in fat mixtures. Food Chem. 92 133-141.http://dx.doi.org/10.1016/j.foodchem.2004.07.010 Talbot G, Smith K, Bhaggan K. 2012. Influence of minor components on fat crystallization. Lipid Technol. 24, 83-85. http://dx.doi.org/10.1002/lite.201200180

Wiedermann L. 1968. Margarine oil formulation and control. J. Am. Oil Chem. Soc. 45, A515-A560. http://dx.doi. org/10.1007/bf02668978 